\title{
Measuring social-ecological resilience reveals opportunities for transforming environmental governance
}

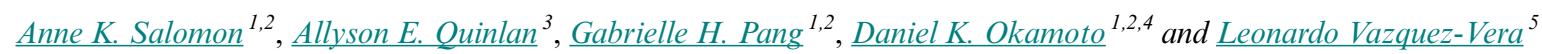

\begin{abstract}
Understanding the resilience of social-ecological systems can advance our ability to transform environmental governance and achieve ecologically sustainable and socially just outcomes. However, measuring this multidimensional emergent system property has been elusive. We translated theoretical principles of resilience into ecological and social metrics and used expert knowledge to assess how they have changed through three sequential governance regimes of the Pacific herring fishery in northwestern Canada. We showed a significant reduction in system-wide resilience between previous Indigenous and historical colonial governance regimes, and limited change with the onset of the latest environmental justice era. We also detected recent signs of recovery among several metrics of resilience, thereby signaling that this system exhibits the preconditions for governance transformation. Pinpointing the erosion and recovery of attributes that confer social-ecological resilience can reveal leverage points and highlight strategic pathways to enable deliberate transformation toward a more ecologically sustainable and socially just future.
\end{abstract}

Key Words: adaptive governance; comanagement; complex adaptive systems; coupled natural and human systems; forage fish; Indigenous fisheries; small-scale fisheries

\section{INTRODUCTION}

Operating within the ecological boundaries of our biosphere (Rockström et al. 2009) while ensuring its equitable use (Raworth 2012) is among the greatest challenges facing humanity in the $21 \mathrm{st}$ century. This requires a deliberate change from business-as-usual environmental governance to approaches that are both ecologically sustainable and socially just. By evaluating cases of governance transformation in small-scale fisheries (Gelcich et al. 2010), marine ecosystem-based management (Olsson et al. 2008), and wetland and freshwater management (Olsson et al. 2004), key phases, processes, and elements of governance transformation have emerged (Olsson et al. 2006, Moore et al. 2014). We advance a method by which to measure social-ecological system (SES) resilience that can reveal leverage points, as well as constraints, to building the resilience of sustainable and just social-ecological systems, and to help guide transformation when systems fail to meet these conditions.

While the scholarly discourse on the relationships between resilience, transformation, and sustainability has lacked consensus and clarity, recent syntheses have helped resolve previous ambiguities and thereby facilitate the practical application of these interlinked but distinct concepts (Folke et al. 2016, Elmqvist et al. 2019). At its core, resilience is the capacity of a system to absorb disturbance and reorganize, as to maintain the same core structure, functions, and feedbacks over time, and thus continue to develop within the bounds of a particular trajectory (Folke et al. 2004, Walker et al. 2004, Folke 2006). In order for a system to maintain its essential identity, it is widely recognized that parts of the system must continuously adapt, and occasionally parts of the system may need to undergo a transformation (Folke et al. 2010, 2016, Elmqvist et al. 2019). In this way, transformation of the governance subsystem, such that it becomes fundamentally different in how it functions, may be key to ensuring the long-term resilience of a sustainable and just social-ecological system.
For more than three decades, translating resilience theory into practice has been limited by a lack of tools to measure SES resilience (Quinlan et al. 2015). Moreover, despite recent advances in operationalizing SES frameworks (Leslie et al. 2015) and assessing SES resilience (Allen et al. 2018), practical applications of these methods for resolving complex natural resource management issues remain rare (Angeler and Allen 2016). Fortunately, the emergence of seven policy-relevant principles for enhancing the resilience of SESs (Biggs et al. 2012) provides a theoretically grounded framework by which to evaluate this emergent system property in practice. A timely opportunity to transform environmental governance with such methods exists, particularly among the world's oceans, where in nearly every country the recovery of depleted fisheries would drive increases in food, profits, and fish biomass in the sea (Costello et al. 2016).

Fisheries are quintessential examples of complex adaptive systems and are managed around the world with a broad range of institutional structures. Poorly performing fisheries, based on social, economic, and ecological measures, have generally involved either open-access policies, top-down regulation with poor local involvement and compliance, and mismatches between the scale of social-ecological processes driving the fishery and the policies intended to manage them (Hilborn et al. 2005, Gutiérrez et al. 2011, Cinner et al. 2012). These issues become increasingly problematic in mixed fisheries where small-scale fishers are limited to adjacent resources, whereas larger, more mobile commercial fleets can continually move to new, underexploited areas (Berkes et al. 2006). Furthermore, the livelihoods and lifestyle objectives of small-scale fishers are rarely valued on par with industrial fishing interests (Plagányi et al. 2013), thereby leading to inequity among actors and ultimately, conflict.

Among small-scale fisheries around the world, a growing number of Indigenous communities have successfully reasserted their rights to access ocean resources, as well as their responsibility to

${ }^{1}$ School of Resource and Environmental Management, Simon Fraser University, ${ }^{2}$ Hakai Institute, ${ }^{3}$ Resilience Alliance, ${ }^{4}$ Department of Biological Sciences, Florida State University, ${ }^{5}$ Comunidad y Biodiversidad A.C. 
manage and conserve them (Turner et al. 2013). This includes both the operational rights to enter a fishery and engage in a specific level of fishing effort, and collective choice rights to participate in the management and governance of a fishery (Schlager and Ostrom 1999). Despite these legal victories, concomitant transformation in natural resource governance that upholds collective choice rights has lagged behind, in part due to a lack of clear direction on what precisely needs to change and how. Consequently, a pressing need exists to develop a method by which leverage points, places to intervene in a system to guide transformation (Meadows 1999, Abson et al. 2017), can be identified in a transparent way and perceived as legitimate by all system actors (Pinkerton and John 2008). Quantifying how multiple dimensions of social-ecological resilience have changed through time can reveal strategic opportunities and leverage points to help guide governance transformation toward a more desired, resilient, and socially just system.

We use the case of Pacific herring (Clupea pallasii) fisheries along the central coast of western Canada (Fig. 1) to simultaneously quantify change in the ecological and social dimensions of resilience. We focused on this forage fish because it has been culturally, ecologically, and economically important to Indigenous people across the entire northeastern Pacific for millennia (McKechnie et al. 2014), has been subject to industrialscale commercial fisheries since the late 1800s (Cleary et al. 2010), and has experienced regional and local population collapses over the past three decades across much of its range (Essington et al. 2015, Okamoto, Hessing-Lewis, Samhouri et al. unpublished manuscript), which has led to fisheries closures and conflict. In western Canada, uncertainty in population estimates and debate over drivers of change, alongside failed comanagement agreements among Indigenous and federal governments, have spurred court injunctions, social unrest, and crises (von der Porten et al. 2016, Jones et al. 2017), emblematic of natural resource conflicts worldwide.

We build on an emerging research frontier that aims to assess SES resilience (Cosens and Fremier 2014, Nemec et al. 2014, Allen et al. 2018) and guide transformation in environmental governance. We advance this field by translating seven theoretical resilience principles (Biggs et al. 2012) into empirical, context-specific metrics and use expert knowledge from traditional resource users to quantify how these metrics have changed through time throughout three dominant governance regimes. Specifically, we used nested ordinal logistic mixed-effects models to quantify the effect of each governance regime on (1) system-wide resilience, (2) each of the seven resilience principles, and (3) all 22 systemspecific resilience metrics. From this analysis, we demonstrate how quantifying changes in the key dimensions of SES resilience based on traditional knowledge from resource experts can help guide recovery from fisheries crises and avert future ones by illuminating strategic opportunities and leverage points to transform fisheries governance in Canada, and natural resource governance broadly.

\section{METHODS}

\section{Social-ecological system}

To identify key components and interactions of the Pacific herring SES and dominant governance regimes along British Columbia (B.C.), Canada's central coast (Fig. 1), we held an expert focus group with multigenerational Indigenous herring fishermen, resource managers, elected and hereditary Chiefs, and elders who were identified as experts (Davis and Wagner 2003, Fazey et al. 2006) in this fishery. Experts were selected by the local Indigenous resource management and stewardship office. Of British Columbia's four central coast Indigenous groups (Fig. 1), selfreferred to as First Nations in Canada, our analysis focused on the Heiltsuk Nation, the largest of four Indigenous communities in the study area whose recent conflict with federal regulating authorities over the management and conservation of herring is illustrative of similar herring-triggered conflict between federal agencies and coastal communities along the entire northeastern Pacific coast (Jones et al. 2017). Participant selection targeted community experts who play a significant role in the local herring fishery and who have high levels of traditional knowledge of the Pacific herring SES, making them ideally suited to detect changes in the characteristics of natural resources and socioeconomic conditions (Berkes et al. 2000, Davis and Wagner 2003). On the basis of this focus group and the published literature, we then generated 22 metrics of resilience (Table 1) that were fine-tuned to the central coast Pacific herring SES.

Fig. 1. Along the northeastern Pacific Ocean, the central coast of British Columbia, Canada is one of five fisheries management areas for Pacific herring (Clupea pallisii). This area has been home to four Indigenous groups, including the Heiltsuk, Nuxalk, Wuikinuxv, and Kitasoo/Xais'Xais First Nations, for at least 14,000 years.

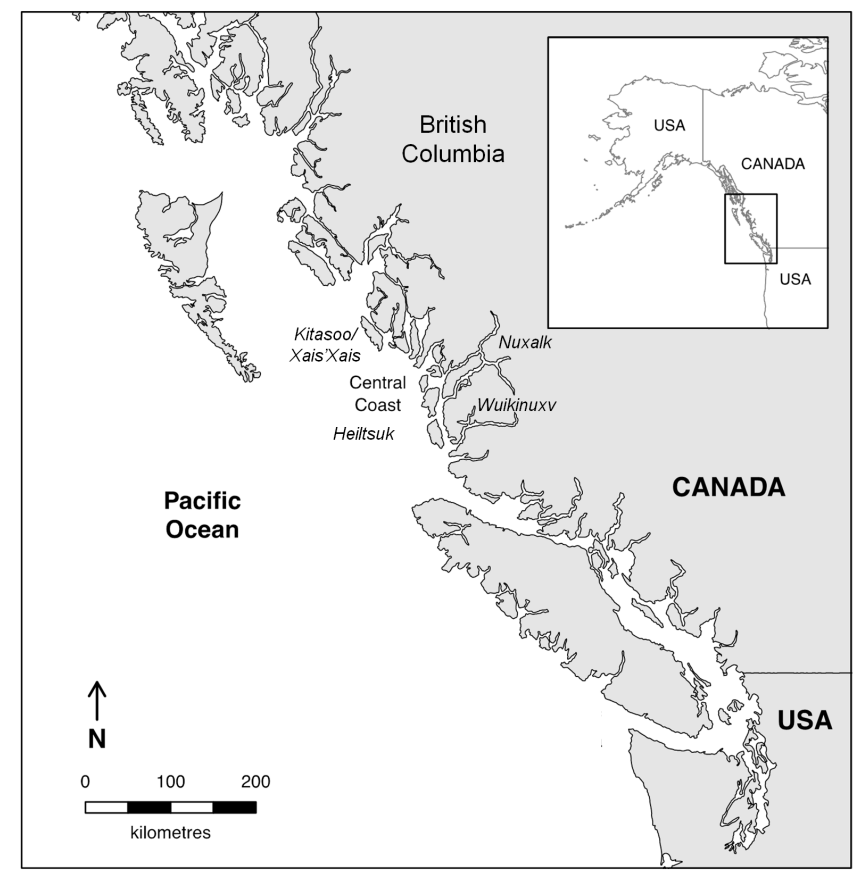

\section{Resilience metrics}

To assess change in the magnitude of each resilience metric during each governance period, we developed a interviewer-administered questionnaire (Briggs 1986) (Table A1.1). We interviewed Heiltsuk traditional knowledge holders who were identified by 
Table 1. Principles and metrics of social-ecological system (SES) resilience used to assess the change in resilience in Canada's central coast Pacific herring SES

\begin{tabular}{ll}
\hline \hline Resilience principle & Metrics specific to herring SES \\
\hline Maintain diversity and redundancy & Marine species and habitat diversity \\
& Species response diversity \\
& Diversity of perspectives \\
& Diversity of livelihoods \\
& Diversity in herring size structure \\
& Diversity in herring spawning season dates \\
& Degree of information sharing \\
Manage connectivity & Understanding of gradual changes \\
Manage slow variables and feedbacks & Decisions updated with new information \\
& Ability of managers to respond to key changes \\
& Willingness to embrace change \\
Foster complex adaptive thinking & Preparedness to cope with unexpected events \\
& Innovation and willingness to experiment \\
Encourage learning & Sharing of scientific resources \\
& Level of participation \\
Broaden participation & Level of trust \\
& Level of cooperation \\
Promote polycentric governance & Use of Indigenous knowledge and stewardship protocols \\
& Distribution of power in decision-making \\
& Accountability \\
& Indigenous authority to access herring \\
& Willingness for conflict resolution \\
\hline
\end{tabular}

the local stewardship office as herring experts $(n=23)$. The questionnaire was specifically designed considering the cultural context of local experts (Briggs 1986, Bernard 2017) and was administered following Heiltsuk research protocols. Each expert ranked metrics on a Likert scale from 1 (low) to 5 (high) for each governance era. During the survey, detailed notes on the observations, hypotheses, and knowledge generated by each question were recorded and transcribed to inform our inference of the quantitative data generated by the questionnaire (Briggs 1986, Bernard 2017). Finally, to reduce uncertainty and increase accuracy of our inferences, we used peer-reviewed published data on herring population, community, and ecosystem dynamics, as well as archaeological records and ethnographies to triangulate the trends in resilience metrics revealed through expert knowledge.

\section{Statistical analyses}

We ran quantitative analyses on 1440 responses to quantify the effect of each governance regime on (1) system-wide resilience, (2) each of the seven resilience principles, and (3) all 22 systemspecific resilience metrics. First, to test for the effect of governance regime on overall Pacific herring SES resilience, we constructed a nested ordinal logistic mixed-effects model with a cumulative link function that accounted for the ranked nature of our data (Carifio and Perla 2007, Hedeker 2008). This model estimated the probability of each governance regime within each principle being at or below a particular ordinal score, while accounting for the correlation among respondents. The effects of Governance Regime, Resilience Principle and their interaction were treated as fixed effects. Because each respondent $(n=23)$ answered 22 questions and the data derived from those questions were not independent, we treated Respondent as a random effect. We used likelihood ratio tests for main effects and interactions and Tukey pair-wise contrasts to evaluate the effect of Governance Regime on each of the seven resilience principles. A spider diagram was used to visualize these results.
Second, to test for the effect of governance regime on each of the 22 resilience metrics, we constructed a second ordinal logistic mixed-effects model, where the effects of Governance Regime, Resilience Metric and their interaction were treated as fixed effects and Respondent was treated as a random effect. We then calculated main effects and Tukey pair-wise contrasts to evaluate the effect of Governance Regime on each of the 22 resilience metrics. Analyses were conducted using the ordinal and lsmeans packages in R (Christensen 2015, Lenth 2016, R Core Team 2017).

\section{Methodological advances, limitations, and assumptions}

Our research was an initial attempt to measure and assess socialecological resilience, an emergent system property that until now has proven to be quantitatively elusive, despite its relevance to sustainability science. By strategically designing context-specific metrics based on well-established theoretical resilience principles, our approach allowed us to indirectly measure SES resilience, here the capacity of the Pacific herring SES to absorb change and adapt while maintaining its core structure and function, by quantifying the ecological and social attributes that confer this system property. Moreover, this general approach allowed us to fine-tune our metrics to this specific SES. Consequently, this method could be used to define context-specific metrics to assess the resilience of SESs worldwide.

While our approach has advanced the field of quantifying socialecological resilience, the nature of our data and research design has several assumptions and limitations. First, our method is susceptible to several sources of uncertainty and bias. What we report is expert observation and knowledge (Fazey et al. 2006) of resilience attributes, not direct measurements per se. For example, experts reported their observations and knowledge of changes in herring sizes during each governance era, not empirical measurements. Moreover, our assessment of resilience was based on one group of experts in the system: Indigenous knowledge 
holders. Like all sources of data, expert observations are subject to observation uncertainty (the difference between an observed value and its true value), process uncertainty (temporal and spatial variation in the true value), and bias (Hilborn and Mangel 1997). For example, respondents who are asked to make comparisons between the past and present are subject to recall bias (Cinner et al. 2015), although empirical evidence suggests that recalled information can have a high degree of accuracy, even after 50 years (Berney and Blane 1997). Nonetheless, all observations made by humans are influenced by their cultural context (Berkes et al. 2000). Lastly, our sample size of experts was relatively small due to the limited pool of experts within the community we could draw on, a challenge that plagues resource systems worldwide.

To reduce the effects of bias and uncertainty in our inference of resilience trends captured in the traditional knowledge of herring experts, we used triangulation by drawing on multiple lines of evidence (Tengö et al. 2014). Specifically, we used diverse sources of data on the herring SES, along with expert observation and knowledge, from which we drew inferences on SES resilience through time. These multiple sources of information are presented and synthesized in our discussion, and weaving them into our assessment is a strength of our method. By drawing on multiple sources of data, not only did we reduce the uncertainties, limitations, and biases of each data stream, we extended the time scale and resolution offered by any one data type alone. Moreover, by using expert knowledge hand-in-hand with peer-reviewed ecological and social data sources, we revealed novel insights into SES dynamics by better grounding our assessment in its sociocultural context (Berkes et al. 2000, Huntington 2000, Salomon et al. 2007, 2018). By doing so, we could more broadly and legitimately inform governance transformations that are both ecologically sustainable and socially just (Fazey et al. 2006, Pinkerton and John 2008, Tengö et al. 2014, 2017, Brondizio and Tourneau 2016, Mistry and Berardi 2016).

Lastly, the notion of resilience is inherently multidimensional, yet not all dimensions are likely to affect system resilience to the same degree. Each of our metrics was considered to have equal importance to system-wide resilience, although this is likely not the case. Differential weighting of resilience attributes according to the SES presents another area for refinement. Furthermore, not all resilience attributes are directly quantifiable (i.e., trust, willingness to embrace change), and perceptions of those attributes are in many cases what matters when it comes to governance transformation (Westley et al. 2011). Fortunately, perceptions by experts may be used to rapidly determine social and ecological status of key system attributes for planning purposes or monitoring changes, particularly in data-deficient situations (Daw et al. 2011, Bennett 2016). A frontier in quantifying SES resilience lies in the integration of empirical measurements of attributes that lend themselves to quantification (i.e., species diversity) with experiential traditional knowledge and equally important but difficult to measure attributes (i.e., perceptions of trust).

\section{RESULTS}

\section{Social-ecological system}

The Pacific herring SES includes three major fisheries that are shaped by cultural traditions, societal norms and values, national legal acts and global declarations, international markets, and oceanographic conditions (Fig. 2A). In the days prior to spawning, industrial mobile commercial fleets target adult female fish for their egg sacs (hereafter "sac-roe" fishery) (Fig. 2B). After spawning, herring eggs collected on submerged vegetation are harvested by local Indigenous fishers for food, social, and ceremonial purposes (hereafter "food" fishery), and for commercial trade (hereafter "spawn-on-kelp" fishery) that supports local Indigenous livelihoods (Fig. 2C). The latter two fisheries are governed by local and regional Indigenous resource management departments that are informed by traditional knowledge, laws and protocols, and are enacted by elected tribal councils and hereditary Chiefs, who hold the rights and responsibility to sustain natural resources and societal well-being in their territories (Fig. 2D). Canada's federal fisheries agency, operating under the mandate of multiple national acts, conducts a single-species stock assessment, sets harvest quotas, and oversees fisheries openings for the two commercial herring fisheries, both of which are influenced by volatile international markets for herring products and are susceptible to political intervention (Bennett 2019). Like all Canadian fisheries, party politics can and do override governance and management policies via ministerial discretion whereby an elected fisheries minister makes the final decision to close or open commercial fisheries regardless of the recommendations of government scientists and managers.

As forage fish, Pacific herring represent a critical link in both open-ocean and coastal food webs, transferring energy from lower to upper trophic levels as individuals and via their spawned eggs, both of which are consumed by a diversity of predators, including piscivorous fish, seabirds, and marine and terrestrial mammals (Fig. 2E). Moreover, the seasonal spawning migration of this pelagic fish to coastal ecosystems represents a significant spatial ecological subsidy, whereby open ocean productivity is transferred to, and fuels, nearshore ecosystems. Lastly, this SES is influenced by natural variation in ocean productivity and temperature anomalies (Cavole et al. 2016).

\section{Governance regimes}

This SES underwent three dominant governance regimes, spanning pre-colonial times until present, which we named the Indigenous governance, colonial control, and environmental justice eras to reflect the principal governance institutions and processes in effect (Fig. 3, see Appendix 2 for details). The Indigenous governance era began at least 2000 years ago and was characterized by extensive trade networks and exclusive rights to ocean spaces held by Chiefs (Powell 2012). Proprietorship, contingent on management that sustained resources within the titleholders' territory, and protocols of reciprocity within and between clans conferred resilience to this SES for at least 2000 years (Trosper 2009) and were likely in effect for prior millennia (Brown and Brown 2009, Lepofsky and Caldwell 2013). The potlatch was the system of governance, widespread along the west coast of Canada, until it was banned by colonial law in 1885 . Despite the imposition of colonial law, potlatches were still practiced in secrecy.

Following this perturbation came the colonial control era, characterized by centralized state-control over fisheries and other aspects of First Nations' society (Harris 2002, Harris 2008). Throughout this era and since then, Canada's federal fisheries 
Fig. 2. A) Key components (rectangles), drivers (ovals), and functional relationships of the Pacific herring social-ecological system; direct link (solid blue arrow), feedback (dashed blue arrow), external link (solid orange arrow). B) Adult female herring are targeted by an industrial, mobile commercial seine fishery prior to spawning. C) After spawning, spawned herring eggs are harvested from anchored vegetation by local Indigenous fisheries for commercial trade and local food, social, and ceremonial use. D) Indigenous Heiltsuk hereditary Chiefs, who hold the responsibility for sustaining their communities' resources and well-being, confront federal fisheries officers in 2015 with their request to close the industrial commercial seine fishery for conservation purposes due to low stock abundances. E) Herring play a pivotal ecological role in pelagic and coastal food webs as prey to a diversity of species, including fish (e.g., salmon, halibut, Pacific cod, hake, rockfish), marine mammals (e.g., humpback whales, sea lions, seals), seabirds, and terrestrial consumers (e.g., coastal wolves, bears). (Photos by I. McAllister)

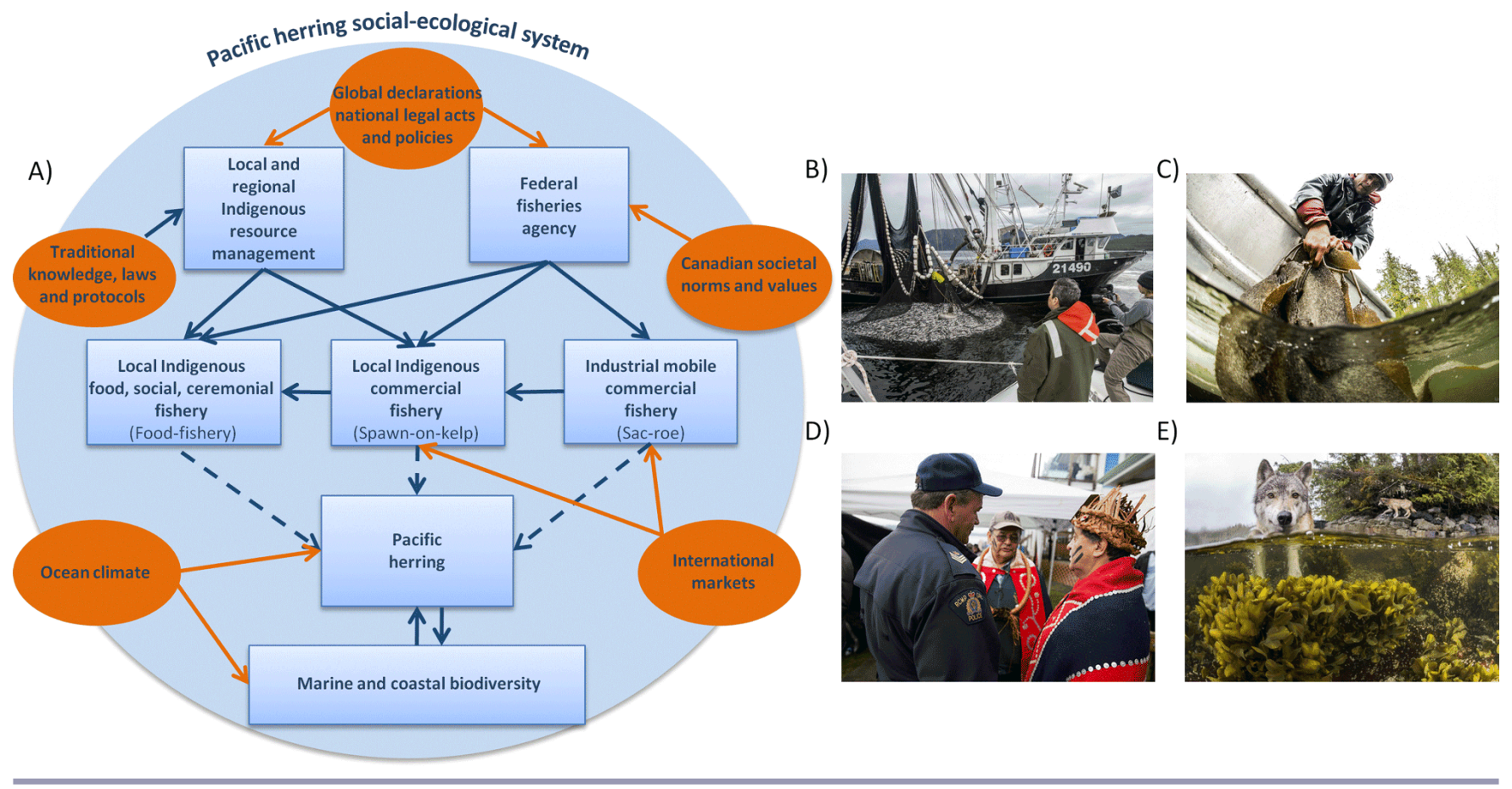

agency has asserted its authority over all fisheries in Canada under the Fisheries Act, even though most coastal Indigenous communities in B.C. have not signed treaties relinquishing ownership or control of their lands and sea.

The recent environmental justice era (Harvey and Braun 1996, Mohai et al. 2009) was triggered by local revolt when Indigenous fishers were excluded from the commercial spawn-on-kelp fishery, a fishery that has been part of the Indigenous economy along the northwest coast of North America for millennia (McKechnie et al. 2014). This led to a precedent-setting Supreme Court case in 1996 that established the Heiltsuk Nation's aboriginal right to commercially trade herring spawn-on-kelp (Harris 2000). The discrepancy between the court's affirmation of aboriginal fishing rights to herring and the translation of these rights into policy by Canada's federal fisheries agency have resulted in coast-wide protests by Indigenous groups from 1998 to present (Powell 2012, von der Porten et al. 2016, Jones et al. 2017). Despite recent localized population collapses in herring biomass on B.C.'s central coast (Okamoto, Hessing-Lewis, Samhouri et al. unpublished manuscript) and conservation concerns by several First Nations communities, Canada's federal fisheries minister opened the commercial herring fishery in 2015 counter to the science-based management recommendation, which triggered the 2015 herring crisis.

\section{Social-ecological system resilience}

While we found a significant effect of governance regime on overall social-ecological system resilience, the magnitude and direction of the effect varied significantly among each of the seven resilience principles and between the three governance regimes (likelihood ratio $\mathrm{X}^{2}=122.3$, df $=18, p<2.2 \mathrm{e}^{-16}$ ) (Fig. 4, Table A3.1). Specifically, we found a significant decline in socialecological Diversity and Redundancy across all three governance regimes (Table A4.1). In contrast, among the remaining six principles, we found a significant decline in resilience with the onset of the colonial governance regime and no significant change in resilience with the arrival of the most recent environmental justice regime. Although not significant, the resilience principles of Learning and Polycentric Governance both tended to be higher, on average, during the most recent environmental justice era compared with the previous colonial control era (Fig. 4).

The effect of governance regime also differed significantly among specific resilience metrics used to assess each resilience principle (likelihood ratio $\mathrm{X}^{2}=259.2, \mathrm{df}=63, p<2.2 \mathrm{e}^{-16}$ ) (Fig. 5, Tables A3.1 and A5.1). Specifically, the diversity of coastal species and habitats, herring sizes, and herring spawn dates exhibited significant declines across all three governance regimes (Fig. 5A), while the diversity of actors' perspectives, livelihoods, and species' responses to disturbances dropped significantly only between the 
Fig. 3. Time line of governance regimes, herring fisheries \& key disturbance events in British Columbia, Canada's central coast Pacific herring social-ecological system, prior to European colonization through to spring 2015.

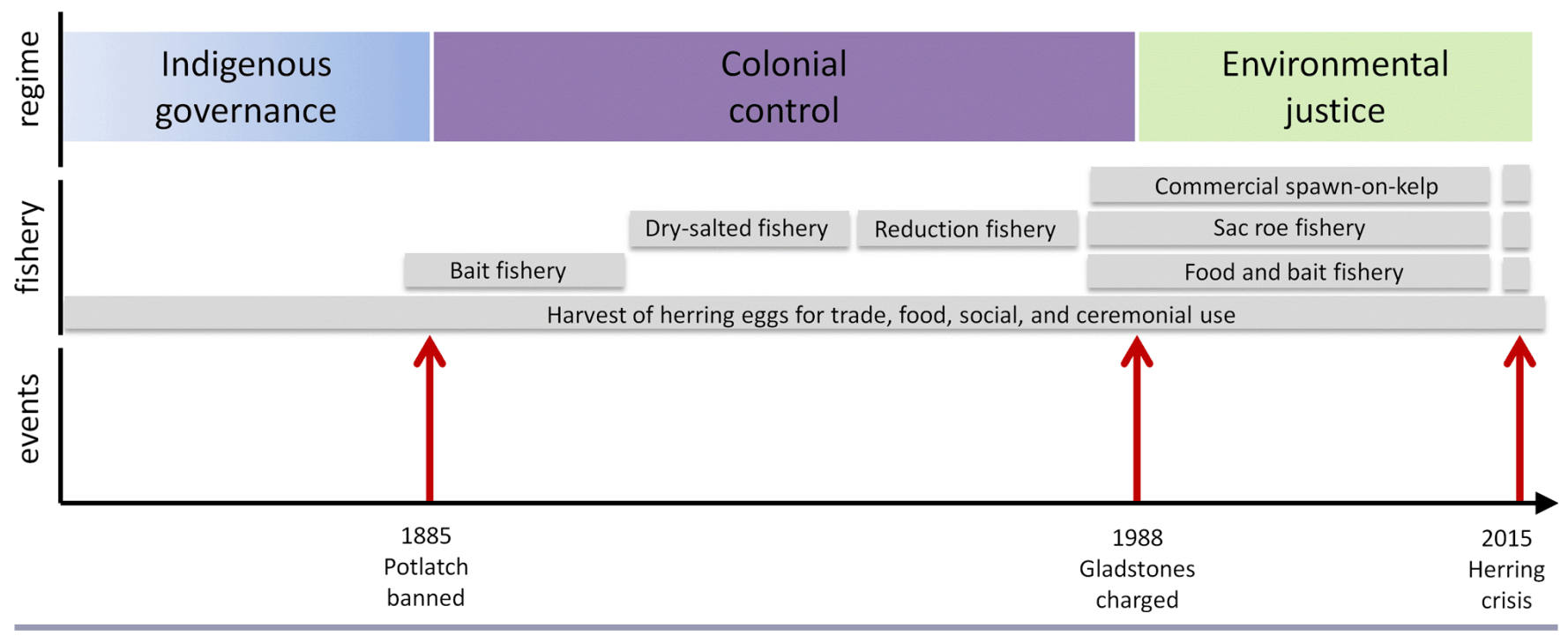

Indigenous and colonial control eras (Fig. 5A). We found significant declines in information sharing, the metric we used to assess the resilience principle of Connectivity, between Indigenous and colonial control eras and no change with the onset of the most recent environmental justice era (Fig 5B). This was also the case for understanding long-term changes and updating decisions with new information, and the ability of managers to respond to disturbances, metrics we used to assess the resilience principle of managing Slow Variables and Feedbacks (Fig 5C).

Fig. 4. Effect of governance regimes on the resilience of Canada's central coast Pacific herring social-ecological system.

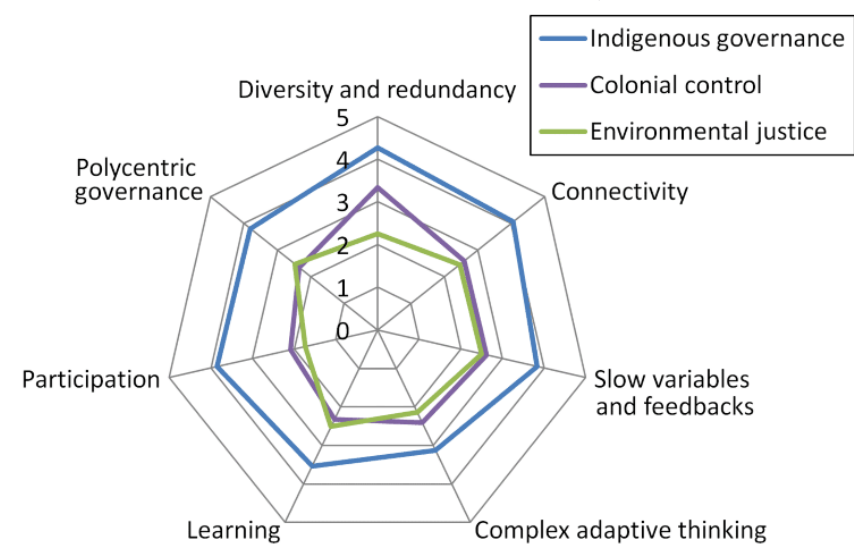

The two metrics we used to assess Complex Adaptive Thinking exhibited different responses to each governance era; while actors' preparedness to cope with unexpected events dropped significantly between the Indigenous and colonial control eras with no change following the environmental justice era, their willingness to embrace change did not differ significantly across all three governance regimes (Fig 5D). Innovation and willingness to experiment, in addition to cooperation, trust, and participation, metrics used to assess the resilience principles of Learning and Participation, respectively, all declined between the Indigenous and colonial control eras with no change since, while the sharing of scientific resources tended to increase during the recent environmental justice era, albeit nonsignificantly (Figs. 5E and $5 \mathrm{~F}$ ). Finally, while the distribution of power in decisionmaking did not change significantly among governance eras, the integration of Indigenous knowledge and stewardship protocols, Indigenous authority to access herring, and willingness for conflict resolution all dropped significantly with the onset of the colonial governance regime and have tended to increase, although nonsignificantly, with the recent environmental justice era (Fig $5 \mathrm{G})$.

\section{DISCUSSION}

Navigating toward ecologically sustainable and socially just operating space is among the foremost challenges facing resource systems globally. While assessing social-ecological system resilience can inform strategic shifts to more sustainable and equitable trajectories, quantifying this multidimensional emergent system property has, until now, been elusive. We advanced a method that allowed us to identify where and by how much SES resilience has both eroded and been enhanced through time. In this case study, we detected a significant reduction in multiple dimensions of SES resilience between the Indigenous and colonial governance eras. Moreover, we found no significant change in system-wide resilience with the onset of the most recent environmental justice regime, with the exception of the resilience principle of Diversity and Redundancy, which exhibited significant declines across all three governance regimes (Fig. 4, Tables A3.1 and A4.1). These declines in system diversity based on expert knowledge are supported by multiple sources of empirical evidence from quantitative scientific sources (Martell et al. 2012, Shelton et al. 2014, Keeling et al. 2017, Okamoto, Hessing-Lewis, Samhouri et al. unpublished manuscript). Importantly, we also detected slight but nonsignificant signs of 
Fig. 5. Effect of governance regimes on specific resilience metrics used to assess change in the resilience of Canada's central coast Pacific herring social-ecological system (mean \pm standard error). Significant differences in resilience metrics among governance eras are denoted by unique letters $(\mathrm{a}, \mathrm{b}$, and $\mathrm{c})$.
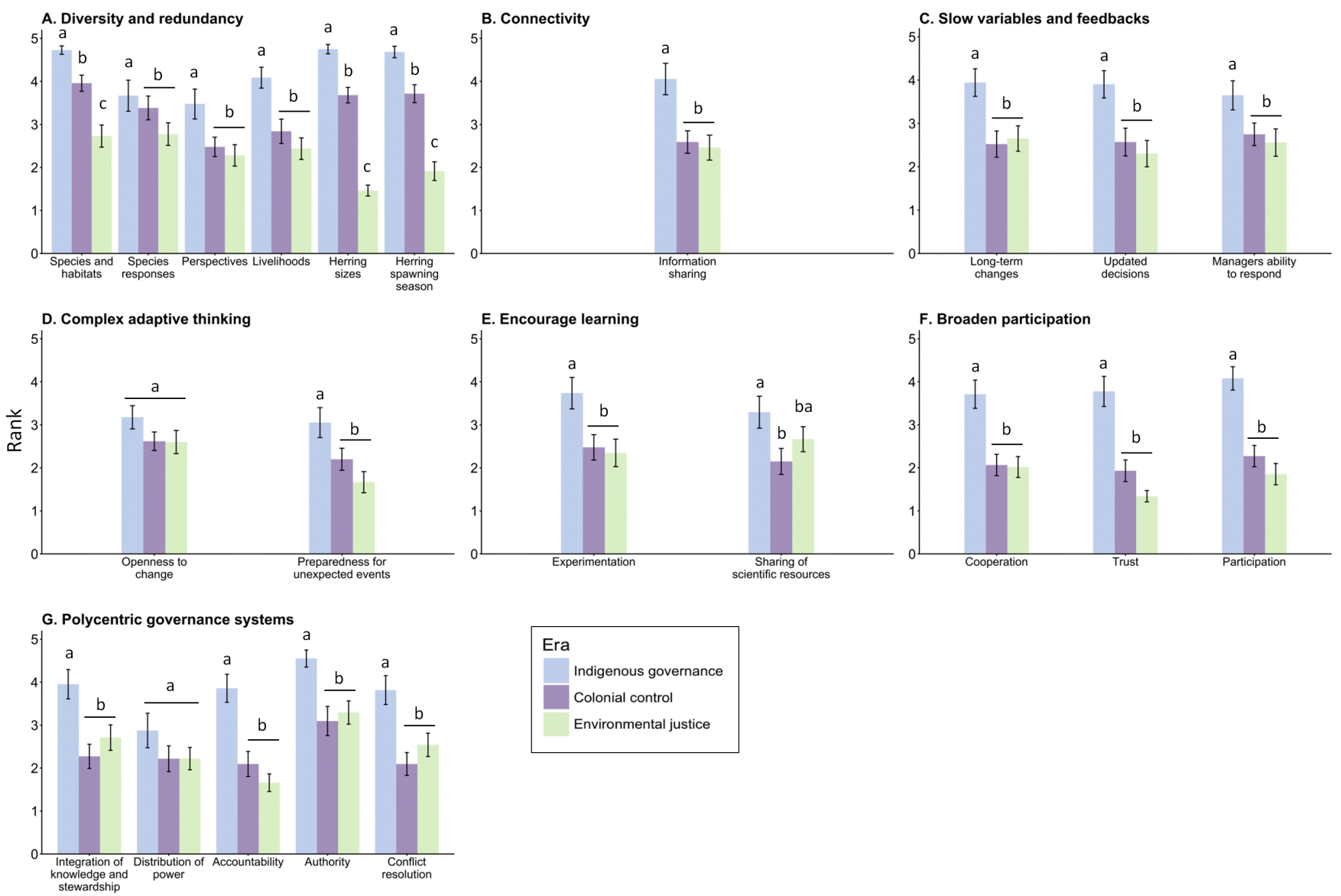

recovery among several resilience metrics in the most recent environmental justice regime (Fig. 5, Table A5.1), thereby signaling the preconditions necessary for transforming fisheries governance in Canada. By translating resilience principles into context-specific metrics and quantifying change in multiple dimensions of resilience simultaneously through time, our analytical approach can reveal strategic opportunities and leverage points for preparing and enabling fisheries governance transformation within the Pacific herring SES and among SESs more broadly. Legacy effects, time lags, and lack of true governance transformation following the colonial governance regime are in part why we did not detect a significant increase in resilience metrics in the much shorter and more recent environmental justice regime, despite the legal affirmation of aboriginal rights to herring that triggered the start of this governance regime (Raudsepp-Hearne et al. 2010, Waylen et al. 2015).

\section{Preconditions for governance transformation}

Transformation has been associated with a subset of preconditions that create opportunities for change. Crisis events, agency among actors, social networks affording political leverage, discovery of new ecological or social phenomena, and new management options revealed through experimentation have all been identified as potential preconditions for governance innovation (Olsson et al. 2006, Gelcich et al. 2010, Moore et al. 2014). Within the most recent environmental justice regime of the Pacific herring SES, our analysis revealed recent signs of recovery among some metrics of Learning and Polycentric Governance, that is nested, semi-autonomous governing bodies that enable experimentation, discovery, and participation among all system actors. Recovery among these metrics suggests enabling preconditions for transformation in fisheries governance exist in this system. Specifically, we detected an increasing trend in the sharing of scientific resources among actors and the integration of Indigenous knowledge and stewardship protocols in contemporary management with the onset of the most recent environmental justice era (Figs. 5E and 5G). These trends may be attributed to the emergence of bridging organizations increasing the social and political capital among previously politically autonomous Indigenous communities (Price et al. 2009, McGee et al. 2010), newly established politically neutral learning-based institutions supporting collaborative research in the area (Salomon et al. 2018), and recent marine planning initiatives co- 
led by federal, provincial, and Indigenous government bodies that are premised on equitable power-sharing relationships.

Within the environmental justice era, we also detected an increase in the ability of local Indigenous governments to exert their traditional authority to access and conserve marine resources, and willingness for negotiation and conflict resolution among actors in the system (Fig. 5G). This reflects increasing coast-wide efforts by First Nations to exert agency in fisheries governance specifically (Jones et al. 2017) and natural resource stewardship more broadly. As a result of the 2015 herring crisis, negotiations between local Indigenous and federal fisheries agencies have led to a new, jointly developed and adopted management plan. Moreover, recent agreements for reconciliation among provincial and local Indigenous governments provide further grounds for power-sharing in the governance of the marine commons. Collectively, these multiple events indicate that this system is at a critical juncture with the potential to move from a centralized management system toward a polycentric one that formalizes shared decision-making and equitable power relationships. If such a governance transformation of this system were to occur, we would expect to see this reflected in an increase in the resilience metrics we quantified for the Pacific herring SES.

\section{Resilience principles reveal challenges and opportunities for navigating transformation}

\section{Maintain diversity and redundancy}

Among the decline in resilience principles detected over time, the most pronounced was the erosion of system Diversity and Redundancy (Fig. 4). Specifically, experts identified a strong reduction in large-sized herring, fewer spawning locations, and reduced spawning season length owing to the loss of outer coast and summer spawn events (Fig. 5A). Multiple sources of empirical evidence support these findings and indicate that herring population size structure, size-at-age, spawning season length, and locations across this region have contracted since the 1980s (Martell et al. 2012, Okamoto, Hessing-Lewis, Samhouri et al. unpublished manuscript).

The attrition of population, life history, and habitat diversity is well known to lead to the erosion of a species' resilience to environmental perturbations (Hilborn et al. 2003). In fact, the erosion of demographic and spatial diversity among exploited populations has been shown to reduce the stability of fished populations (Anderson et al. 2008), including sockeye salmon (Schindler et al. 2010), and Pacific herring metapopulations (Siple and Francis 2016). Not only do larger and older age classes of fish increase reproductive potential and buffer a population against recruitment failure (Essington et al. 2015), a reduction in fish size classes and spawning populations can erode the diversity of responses to environmental change (Elmqvist et al. 2003), a dimension of resilience that was also observed to have declined in the B.C. system (Fig 5A). Lastly, the loss of larger, older, and experienced fish can lead to the loss of spawning area and migration knowledge transmitted to first-time spawners (McQuinn 1997). This loss of intergenerational knowledge transmission has been proposed to erode the modular spatial structure among herring subpopulations, rendering them more susceptible to collapse and impairing recovery post collapse (Rogers et al. 2018).
There are a number of opportunities at multiple scales of governance to address declines in diversity and redundancy in fisheries-based SESs. At the global scale, leadership in sustainability by keystone seafood businesses, which disproportionately influence financial markets, would enable improved governance of exploited marine species and ecosystems more broadly (Österblom et al. 2015). Engaging seafood businesses to reject unsustainable growth-oriented goals and support broader social values while remaining within ecosystem thresholds represents a type of deep leverage point that addresses the values and goals underpinning complex problems and is therefore likely to lead to profound change (Abson et al. 2017).

While most fisheries in Canada are managed using single-species, biomass-based assessments and objectives, evidence from fisheries worldwide suggest that a leverage point at the national scale lies in broadening this status quo. Today, many developed nations are aiming to transition toward ecosystem-based management. Despite these efforts, and in some cases legislative requirements, shifts toward this approach are often constrained by a lack of enabling legislation, institutional inflexibility, poor socioeconomic incentives, and inequitable power relations among actors (Gelcich et al. 2010). Evidence from SESs elsewhere suggest that including lifestyle and livelihood objectives of historically marginalized actors (Plagányi et al. 2013) and sustainable targets for nonhuman consumers (Essington et al. 2015) could go a long way in shifting this SES toward more resilient trajectories. Furthermore, management strategies that maintain diverse local spawning subpopulations could increase the stability of regional herring biomass (Siple and Francis 2016), and reduce spatial inequity in access to this resource and its risk of local collapse (Okamoto, Hessing-Lewis, Samhouri et al. unpublished manuscript).

Locally, designated community access privileges, licensing rules that allow fishers to switch among fisheries and gear types, and social programs that support occupational multiplicity and mobility would enable fishers to respond and adapt to changes in resource availability, environmental conditions, and/or financial market fluctuations. Across Latin America, community-oriented rules and allocation of exclusive access rights to fish in geographically designated areas has been a key factor in enabling successful management of the marine commons (Defeo and Castilla 2005, Gelcich et al. 2010, McCay et al. 2014). Moreover, community access rights to a diversity of marine resources and other economic activities could broaden the livelihood diversity and economic portfolio of Indigenous coastal communities across B.C., thereby increasing their resilience to external perturbations. Although application of the concept of exclusive spatial access rights to a marine area is rare today in North America, designated access rights were a key component of traditional marine stewardship practices among Indigenous communities throughout the Pacific Ocean, including the northwest coast of North America (Trosper 2009, Powell 2012) and Oceania (Johannes 2002). While this and locally based fishing regulations might require a more sophisticated and costly management strategy than is currently used for Pacific herring, this may be an effective way to avoid local population collapses (Okamoto, Hessing-Lewis, Samhouri et al. unpublished manuscript), reduce conflict, and enhance the resilience of this entire system. Offering strong community-held and community- 
designed exclusive rights in exchange for establishing spatial protection to recover depleted species could function as strong local incentive to avoid further declining trends in system diversity and redundancy.

\section{Manage connectivity, slow variables, and feedbacks}

The degree of information sharing among actors, our metric for system Connectivity, declined significantly after the local Indigenous governance system informed by traditional, placebased knowledge and practices was replaced by centralized colonial institutions, with no detectable change since (Fig. 5B). Moreover, the understanding of long-term changes (e.g., ocean productivity, value systems), the flexibility of managers to update decisions with new information, and their ability to respond to change all declined significantly with the onset of the colonial governance era, again with no detectable change since (Fig. 5C). To address declines in information sharing, bridging actors such as academic researchers could facilitate the exchange of information among federal, provincial, and Indigenous resource agencies. This would also serve to increase the ability of local and federal managers to update decisions and respond to short- and long-term drivers of change.

Foster complex adaptive systems thinking and encourage learning Despite clear dissatisfaction by the Indigenous community over how herring are currently managed (von der Porten et al. 2016, Jones et al. 2017), federal institutions have been resistant to change (Fig. 5D). Codeveloping future management scenarios and experimentally testing alternative management policies has been shown to help coastal communities learn and prepare for unexpected events (Daw et al. 2015, Oteros-Rozas et al. 2015). Similarly, scenarios as stories can help with challenging existing narratives and understanding people's assumptions about how a system works (Galafassi et al. 2018). Borrowing from the toolkits of participatory scenario planning and adaptive comanagement (Armitage et al. 2009) would foster both Complex Adaptive Systems Thinking and Learning.

\section{Broaden participation and promote polycentric governance}

Levels of cooperation, trust, and participation among system actors, all metrics for Broadening Participation, diminished significantly from the Indigenous to colonial governance era with no significant change since (Fig. $5 \mathrm{~F}$ ). This was also the case for four of five metrics of Polycentric Governance, including accountability, authority, conflict resolution, and knowledge integration, the latter three metrics showing a slight but nonsignificant recent increase (Fig. 5G).

Consequently, a key opportunity for transforming fisheries governance in Canada lies in creating legislation and policies that support equitable authority and shared power between federal and Indigenous fisheries managers, thereby institutionalizing aboriginal rights, including both collective choice rights to manage and conserve these fish, and operational rights to access them (Jones et al. 2017). Equally as important are the processes that support these legal instruments. Establishing collaborative management (Armitage et al. 2009) and promoting polycentric governance arrangements are ways to help achieve adaptive governance, which includes learning-based, decision-making processes that involve both state and nonstate actors, and aims to negotiate and coordinate management that accommodates diverse perspectives, creating opportunities for shared learning and trust building.
Evidence from multiple natural resource systems across the world suggests that adaptive governance is more likely to lead to successful ecosystem-based management than most current approaches because it is well-suited to contexts of change, complexity, uncertainty, and diverse knowledge systems (Schultz et al. 2015). By engaging diverse user groups, this approach to natural resource governance facilitates the use of multiple sources of evidence, which can include both traditional knowledge and western science. Cases from around the world provide strong evidence that integrating traditional knowledge into the monitoring and management process can reveal essential behavioral and demographic features of target species (Johannes et al. 2000), extend temporal scales of data and illuminate key SES dynamics (Salomon et al. 2007, Lee et al. 2018), generate new insights for marine governance (Cinner and Aswani 2007), and recover depleted populations (Castello et al. 2009).

\section{Window of opportunity}

Transformation in governance often requires the emergence of a window of opportunity (Olsson et al. 2006, Chapin et al. 2010). Following 10 years of a conservative government in Canada, a political and legislative window of opportunity now exists to transform fisheries governance. A recent national reconciliation commission and legal reform, including Canada's ratification of the United Nations Declaration on the Rights of Indigenous Peoples, are indicative of the current federal government's increased action on Indigenous issues. Moreover, new evidence points to a social tipping point in Canadian social norms and values toward supporting Indigenous rights and recognizing previous injustices (Neuman 2016). These international and national contexts expose additional leverage points for change at higher levels of governance.

\section{Guiding governance transformation in the Anthropocene}

Despite the urgency and possibilities for transformation in the Anthropocene, disrupting the inertia of entrenched governance systems that are failing to meet social, ecological, and economic outcomes remains a significant challenge (Chaffin and Gunderson 2016). Analyses of such transformations have revealed preconditions for enabling change, as well as catalysts that trigger governance innovations and the mechanisms that build and sustain resilience of more desirable regimes (Olsson et al. 2006, Gelcich et al. 2010). We make headway at this research frontier by advancing a method that both quantifies SES resilience and operationalizes the concept in that it illuminates leverage points and constraints for governance transformation. This generalizable approach can inform all three phases of the transformation process by enabling scholars and practitioners to (1) assess preconditions for transformation, (2) identify barriers and leverage points to navigate transformation, and (3) highlight where to build resilience of newly transformed and desirable systems.

Windows of opportunity play an important role in transformation processes and often follow periods of political turbulence, system collapse, conflict and opposition, shifting social norms, and disruptive or catalytic innovation (Westley et al. 2011, Chaffin and Gunderson 2016). While windows of opportunity may be fleeting, governance transformation can take decades (Westley et al. 2013), thereby revealing the need for intergenerational and coalitions of change makers who are poised to take advantage of new opportunities as they emerge. 
Understanding progress toward creating preconditions for transformation as well as targeted knowledge of barriers and where to intervene in a system can be developed as part of a longer term "readiness" strategy for transforming systems.

Governance transformation itself needs to be supported by enabling legislation. In the case of fisheries governance in Canada, this includes the devolution of power and assigning rights and responsibilities to Indigenous governments to collectively manage and conserve coastal fisheries. Navigating the transition phase of governance innovations can be aided by learning and evidencebased institutions that act as intermediaries that provide relatively neutral ground, independent from policy and politics. Once transformed, building resilience of a new governance regime requires early assessments as a mechanism by which to fine-tune the learning process, build legitimacy, and gain political acceptability of the new policy arrangement (Gelcich et al. 2010).

Transforming institutions that are on trajectories of environmental degradation and social injustice to ones that favor long-term resilience, equity, and justice is the foremost goal of sustainability. By revealing the decline and recovery in contextspecific attributes that confer resilience to a coupled socialecological system, our integrated analysis advances a generalizable method to enable transformation in natural resource governance. A strong understanding of the attributes that confer SES resilience, and how they are changing over time, can inform the transformation processes and provide the empirical basis to substantiate and catalyze bold change.

Responses to this article can be read online at: http://www.ecologyandsociety.org/issues/responses. $\mathrm{php} / 11044$

\section{Acknowledgments:}

We thank H. Humchitt, K. Brown, S. Anderson Behn, J. Carpenter, and $A$. Frid for codesigning this research, B. Gladstone, $K$. Gladstone, F. Reid, M. Reid, G. Housty, and C. Housty for earlier discussions that illuminated key components of this SES, as well as J. Nielsen, S. Chastain, F. Mello, K. Peetoom, and T. Gui for their assistance in collecting data. The Heiltsuk Integrated Resource Management Department, Wuikinuxv Stewardship Office, Central Coast Indigenous Resource Alliance, and Hakai Institute provided logistical support. Constructive insights from C. Allen, K. Brown, A. Cooper, T. Essington, A. Frid, D. Goffner, L. Gunderson, and R. Jones improved this manuscript. Funding was provided by an NSERC Strategic Project Grant \#447247-13 and Simon Fraser University Collaborative Teaching award to AKS.

\section{LITERATURE CITED}

Abson, D. J., J. Fischer, J. Leventon, J. Newig, T. Schomerus, U. Vilsmaier, H. von Wehrden, P. Abernethy, C. D. Ives, and N. W. Jager. 2017. Leverage points for sustainability transformation. Ambio 46(1):30-39. https://doi.org/10.1007/s13280-016-0800-y

Allen, C. R., H. E. Birge, D. C. Angeler, C. A. Arnold, B. C. Chaffin, D. A. DeCaro, A. S. Garmestani, and L. Gunderson. 2018. Quantifying uncertainty and trade-offs in resilience assessments. Ecology and Society 23(1):3. https://doi.org/10.5751/ ES-09920-230103

Anderson, C. N., C.-h. Hsieh, S. A. Sandin, R. Hewitt, A. Hollowed, J. Beddington, R. M. May, and G. Sugihara. 2008. Why fishing magnifies fluctuations in fish abundance. Nature 452 (7189):835-839. https://doi.org/10.1038/nature06851

Angeler, D. G., and C. R. Allen. 2016. Quantifying resilience. Journal of Applied Ecology 53(3):617-624. https://doi. org/10.1111/1365-2664.12649

Armitage, D. R., R. Plummer, F. Berkes, R. I. Arthur, A. T. Charles, I. J. Davidson-Hunt, A. P. Diduck, N. C. Doubleday, D. S. Johnson, M. Marschke, P. McConney, E. W. Pinkerton, and E. K. Wollenberg. 2009. Adaptive co-management for socialecological complexity. Frontiers in Ecology and the Environment 7(2):95-102. https://doi.org/10.1890/070089

Bennett, N. J. 2016. Using perceptions as evidence to improve conservation and environmental management. Conservation Biology 30(3):582-592. https://doi.org/10.1111/cobi.12681

Bennett, N. J. 2019. In political seas: engaging with political ecology in the ocean and coastal environment. Coastal Management 47(1):67-87. https://doi.org/10.1080/08920753.2019.1540905

Berkes, F., J. Colding, and C. Folke. 2000. Rediscovery of traditional ecological knowledge as adaptive management. Ecological Applications 10(5):1251-1262. https://doi.org/10.1890/1051-0761 (2000)010[1251:ROTEKA]2.0.CO;2

Berkes, F., T. P. Hughes, R. S. Steneck, J. A. Wilson, D. R. Bellwood, B. Crona, C. Folke, L. H. Gunderson, H. M. Leslie, J. Norberg, M. Nystrom, P. Olsson, H. Osterblom, M. Scheffer, and B. Worm. 2006. Globalization, roving bandits, and marine resources. Science 311(5767):1557-1558. https://doi.org/10.1126/ science. 1122804

Bernard, H. R. 2017. Research methods in anthropology: qualitative and quantitative approaches. Rowman \& Littlefield.

Berney, L. R. and D. B. Blane. 1997. Collecting retrospective data: accuracy of recall after 50 years judged against historical records. Social Science \& Medicine 45(10):1519-1525. https://doi. org/10.1016/S0277-9536(97)00088-9

Biggs, R., M. Schlüter, D. Biggs, E. L. Bohensky, S. BurnSilver, G. Cundill, V. Dakos, T. M. Daw, L. S. Evans, K. Kotschy, A. M. Leitch, C. Meek, A. Quinlan, C. Raudsepp-Hearne, M. D. Robards, M. L. Schoon, L. Schultz, and P. C. West. 2012. Toward principles for enhancing the resilience of ecosystem services. Annual Review of Environment and Resources 37:421-448. https:// doi.org/10.1146/annurev-environ-051211-123836

Briggs, C. L. 1986. Learning how to ask: a sociolinguistic appraisal of the role of the interview in social science research. Cambridge University Press. https://doi.org/10.1017/CBO9781139165990

Brondizio, E. S. and F.-M. L. Tourneau. 2016. Environmental governance for all. Science 352(6291):1272-1273. https://doi. org/10.1126/science.aaf5122

Brown, F. and Y. K. Brown. 2009. Staying the course, staying alive - Coastal First Nations fundamental truths: biodiversity, stewardship and sustainability. Biodiversity BC, Victoria, British Columbia, Canada. 
Carifio, J., and R. J. Perla. 2007. Ten common misunderstandings, misconceptions, persistent myths and urban legends about Likert scales and Likert response formats and their antidotes. Journal of Social Sciences 3(3):106-116. https://doi.org/10.3844/jssp.2007.106.116

Castello, L., J. P. Viana, G. Watkins, M. Pinedo-Vasquez, and V. A. Luzadis. 2009. Lessons from integrating fishers of Arapaima in small-scale fisheries management at the Mamirauá Reserve, Amazon. Environmental Management 43(2):197-209. https://doi. org/10.1007/s00267-008-9220-5

Cavole, L. M., A. M. Demko, R. E. Diner, A. Giddings, I. Koester, C. Pagniello, M. L. Paulsen, A. Ramirez-Valdez, S. M. Schwenck, N. K. Yen, M. E. Zill, and P. J. S. Franks. 2016. Biological impacts of the 2013-2015 warm-water anomaly in the Northeast Pacific: winners, losers, and the future. Oceanography 29(2):273-285. https://doi.org/10.5670/oceanog.2016.32

Chaffin, B. C., and L. H. Gunderson. 2016. Emergence, institutionalization and renewal: rhythms of adaptive governance in complex social-ecological systems. Journal of Environmental Management 165:81-87. https://doi.org/10.1016/j.jenvman.2015.09.003

Chapin, F. S., S. R. Carpenter, G. P. Kofinas, C. Folke, N. Abel, W. C. Clark, P. Olsson, D. M. S. Smith, B. Walker, and O. R. Young. 2010. Ecosystem stewardship: sustainability strategies for a rapidly changing planet. Trends in Ecology \& Evolution 25 (4):241-249. https://doi.org/10.1016/j.tree.2009.10.008

Christensen, R. H. B. 2015. Ordinal-regression models for ordinal data. $\mathrm{R}$ package version 2015.6-28.

Cinner, J. E., and S. Aswani. 2007. Integrating customary management into marine conservation. Biological Conservation 140(3-4):201-216. https://doi.org/10.1016/j.biocon.2007.08.008

Cinner, J. E., C. Huchery, C. C. Hicks, T. M. Daw, N. Marshall, A. Wamukota, and E. H. Allison. 2015. Changes in adaptive capacity of Kenyan fishing communities. Nature Climate Change 5(9):872-876. https://doi.org/10.1038/nclimate2690

Cinner, J. E., T. R. McClanahan, M. A. MacNeil, N. A. Graham, T. M. Daw, A. Mukminin, D. A. Feary, A. L. Rabearisoa, A. Wamukota, N. Jiddawi, et al. 2012. Comanagement of coral reef social-ecological systems. Proceedings of the National Academy of Sciences of the United States of America 109(14):5219-5222. https://doi.org/10.1073/pnas.1121215109

Cleary, J. S., S. P. Cox, and J. F. Schweigert. 2010. Performance evaluation of harvest control rules for Pacific herring management in British Columbia, Canada. ICES Journal of Marine Science 67(9):2005-2011. https://doi.org/10.1093/icesjms/ $\underline{\text { fsq129 }}$

Cosens, B., and A. Fremier. 2014. Assessing system resilience and ecosystem services in large river basins: a case study of the Columbia River basin. Idaho Law Review 51:91-125.

Costello, C., D. Ovando, T. Clavelle, C. K. Strauss, R. Hilborn, M. C. Melnychuk, T. A. Branch, S. D. Gaines, C. S. Szuwalski, R. B. Cabral, D. N. Rader, and A. Leland. 2016. Global fishery prospects under contrasting management regimes. Proceedings of the National Academy of Sciences of the United States of America 113(18):5125-5129. https://doi.org/10.1073/pnas.1520420113
Davis, A., and J. R. Wagner. 2003. Who knows? On the importance of identifying "experts" when researching local ecological knowledge. Human Ecology 31(3):463-489. https://doi.org/10.1023/ A:1025075923297

Daw, T. M., S. Coulthard, W. W. Cheung, K. Brown, C. Abunge, D. Galafassi, G. D. Peterson, T. R. McClanahan, J. O. Omukoto, and L. Munyi. 2015. Evaluating taboo trade-offs in ecosystems services and human well-being. Proceedings of the National Academy of Sciences of the United States of America 112 (22):6949-6954. https://doi.org/10.1073/pnas.1414900112

Daw, T. M., J. Robinson, and N. A. Graham. 2011. Perceptions of trends in Seychelles artisanal trap fisheries: comparing catch monitoring, underwater visual census and fishers' knowledge. Environmental Conservation 38(1):75-88. https://doi.org/10.1017/ S0376892910000901

Defeo, O., and J. C. Castilla. 2005. More than one bag for the world fishery crisis and keys for co-management successes in selected artisanal Latin American shellfisheries. Reviews in Fish Biology and Fisheries 15(3):265-283. https://doi.org/10.1007/ s11160-005-4865-0

Elmqvist, T., E. Andersson, N. Frantzeskaki, T. McPhearson, P. Olsson, O. Gaffney, K. Takeuchi, and C. Folke. 2019. Sustainability and resilience for transformation in the urban century. Nature Sustainability 2(4):267-273. https://doi. org/10.1038/s41893-019-0250-1

Elmqvist, T., C. Folke, M. Nyström, G. Peterson, J. Bengtsson, B. Walker, and J. Norberg. 2003. Response diversity, ecosystem change, and resilience. Frontiers in Ecology and the Environment 1(9):488-494. https://doi.org/10.1890/1540-9295(2003)001[0488: RDECAR]2.0.CO;2

Essington, T. E., P. E. Moriarty, H. E. Froehlich, E. E. Hodgson, L. E. Koehn, K. L. Oken, M. C. Siple, and C. C. Stawitz. 2015. Fishing amplifies forage fish population collapses. Proceedings of the National Academy of Sciences of the United States of America 112(21):6648-6652. https://doi.org/10.1073/pnas. 1422020112

Fazey, I., J. A. Fazey, J. G. Salisbury, D. B. Lindenmayer, and S. Dovers. 2006. The nature and role of experiential knowledge for environmental conservation. Environmental Conservation 33 (1):1-10. https://doi.org/10.1017/S037689290600275X

Folke, C. 2006. Resilience: the emergence of a perspective for social-ecological systems analyses. Global Environmental Change 16(3):253-267. https://doi.org/10.1016/j.gloenvcha.2006.04.002

Folke, C., R. Biggs, A. V. Nyström, B. Reyers, and J. Rockström. 2016. Social-ecological resilience and biosphere-based sustainability science. Ecology and Society 21(3):41. https://doi.org/10.5751/ ES-08748-210341

Folke, C., S. Carpenter, B. Walker, M. Scheffer, T. Chapin, and J. Rockström. 2010. Resilience thinking: integrating resilience, adaptability and transformability. Ecology and Society 15(4):20. https://doi.org/10.5751/ES-03610-150420

Folke, C., S. Carpenter, B. Walker, M. Scheffer, T. Elmqvist, L. Gunderson, and C. S. Holling. 2004. Regime shifts, resilience, and biodiversity in ecosystem management. Annual Review of Ecology, Evolution, and Systematics 35:557-581. https://doi. org/10.1146/annurev.ecolsys.35.021103.105711 
Galafassi, D., T. M. Daw, M. Thyresson, S. Rosendo, T. Chaigneau, S. Bandeira, L. Munyi, I. Gabrielsson, and K. Brown. 2018. Stories in social-ecological knowledge cocreation. Ecology and Society 23(1):23. https://doi.org/10.5751/ES-09932-230123

Gelcich, S., T. P. Hughes, P. Olsson, C. Folke, O. Defeo, M. Fernández, S. Foale, L. H. Gunderson, C. Rodriguez-Sickert, M. Scheffer, R. S. Steneck, and J. C. Castilla. 2010. Navigating transformations in governance of Chilean marine coastal resources. Proceedings of the National Academy of Sciences of the United States of America 107(39):16794-16799. https://doi. org/10.1073/pnas.1012021107

Gutiérrez, N. L., R. Hilborn, and O. Defeo. 2011. Leadership, social capital and incentives promote successful fisheries. Nature 470(7334):386-389. https://doi.org/10.1038/nature09689

Harris, D. C. 2000. Territoriality, aborigional rights, and the Heiltsuk spawn-on-kelp fishery. University of British Columbia Law Review 34(1):195-238.

Harris, D. C. 2008. Landing native fisheries: Indian reserves and fishing rights in British Columbia. UBC Press, Vancouver, British Columbia, Canada.

Harris, R. C. 2002. Making native space: colonialism, resistance, and reserves in British Columbia. UBC Press, Vancouver, British Columbia, Canada.

Harvey, D., and B. Braun. 1996. Justice, nature and the geography of difference. Blackwell Oxford.

Hedeker, D. 2008. Multilevel models for ordinal and nominal variables. Pages 237-274 in J. de Leeuw and E. Meijer, editors. Handbook of multilevel analysis. Springer, New York, USA. https://doi.org/10.1007/978-0-387-73186-5 6

Hilborn, R., and M. Mangel. 1997. The ecological detective: confronting models with data. Princeton University Press.

Hilborn, R., J. M. Orensanz, and A. M. Parma. 2005. Institutions, incentives and the future of fisheries. Philosophical Transactions of the Royal Society B-Biological Sciences 360(1453):47-57. https://doi.org/10.1098/rstb.2004.1569

Hilborn, R., T. P. Quinn, D. E. Schindler, and D. E. Rogers. 2003. Biocomplexity and fisheries sustainability. Proceedings of the National Academy of Sciences of the United States of America 100(11):6564-6568. https://doi.org/10.1073/pnas.1037274100

Huntington, H. P. 2000. Using traditional ecological knowledge in science: methods and applications. Ecological Applications 10:1270-1274. https://doi.org/10.1890/1051-0761(2000)010[1270: UTEKIS]2.0.CO;2

Johannes, R. E. 2002. The renaissance of community-based marine resource management in Oceania. Annual Review of Ecology and Systematics 33:317-340. https://doi.org/10.1146/ annurev.ecolsys.33.010802.150524

Johannes, R. E., M. M. Freeman, and R. J. Hamilton. 2000. Ignore fishers' knowledge and miss the boat. Fish and Fisheries 1 (3):257-271.

Jones, R., C. Rigg, and E. Pinkerton. 2017. Strategies for assertion of conservation and local management rights: a Haida Gwaii herring story. Marine Policy 80:154-167. https://doi.org/10.1016/ j.marpol.2016.09.031
Keeling, B., M. Hessing-Lewis, C. Housty, D. K. Okamoto, E. J. Gregr, and A. K. Salomon. 2017. Factors driving spatial variation in egg survival of an ecologically and culturally important forage fish. Aquatic Conservation: Marine and Freshwater Ecosystems 27 (4):814-827. https://doi.org/10.1002/aqc. 2757

Lee, L. C., J. Thorley, J. Watson, M. Reid, and A. K. Salomon. 2018. Diverse knowledge systems reveal social-ecological dynamics that inform species conservation status. Conservation Letters 12(2):e12613. https://doi.org/10.1111/conl.12613

Lenth, R. V. 2016. Least-squares means: the R Package lsmeans. Journal of Statistical Software 69(1):1-33. https://doi. org/10.18637/jss.v069.i01

Lepofsky, D., and M. Caldwell. 2013. Indigenous marine resource management on the Northwest Coast of North America. Ecological Processes 2:12. https://doi.org/10.1186/2192-1709-2-12

Leslie, H. M., X. Basurto, M. Nenadovic, L. Sievanen, K. C. Cavanaugh, J. J. Cota-Nieto, B. E. Erisman, E. Finkbeiner, G. Hinojosa-Arango, M. Moreno-Baez, S. Nagavarapu, S. M. W. Reddy, A. Sanchez-Rodriguez, K. Siegel, J. J. UlibarriaValenzuela, A. H. Weaver, and O. Aburto-Oropeza. 2015. Operationalizing the social-ecological systems framework to assess sustainability. Proceedings of the National Academy of Sciences of the United States of America 112(19):5979-5984. https://doi.org/10.1073/pnas.1414640112

Martell, S. J., J. F. Schweigert, V. Haist, and J. S. Cleary. 2012. Moving towards the sustainable fisheries framework for Pacific herring: data, models and alternative assumptions; stock assessment and management advice for the British Columbia Pacific herring stocks: 2011 assessment and 2012 forecasts. Research Document 2011/135, DFO Canadian Science Advisory Secretariat, Ottawa, Ontario, Canada.

McCay, B. J., F. Micheli, G. Ponce-Díaz, G. Murray, G. Shester, S. Ramirez-Sanchez, and W. Weisman. 2014. Cooperatives, concessions, and co-management on the Pacific coast of Mexico. Marine Policy 44:49-59. https://doi.org/10.1016/j.marpol.2013.08.001

McGee, G., A. Cullen, and T. Gunton. 2010. A new model for sustainable development: a case study of The Great Bear Rainforest regional plan. Environment, Development and Sustainability 12(5):745-762. https://doi.org/10.1007/s10668-009-9222-3

McKechnie, I., D. Lepofsky, M. L. Moss, V. L. Butler, T. J. Orchard, G. Coupland, F. Foster, M. Caldwell, and K. Lertzman. 2014. Archaeological data provide alternative hypotheses on Pacific herring (Clupea pallasii) distribution, abundance, and variability. Proceedings of the National Academy of Sciences of the United States of America 111(9):E807-E816. https://doi. org/10.1073/pnas.1316072111

McQuinn, I. H. 1997. Metapopulations and the Atlantic herring. Reviews in Fish Biology and Fisheries 7(3):297-329. https://doi. org/10.1023/A:1018491828875

Meadows, D. H. 1999. Leverage points: places to intervene in a system. The Sustainability Institute, Hartland, Vermont, USA.

Mistry, J., and A. Berardi. 2016. Bridging indigenous and scientific knowledge. Science 352(6291):1274-1275. https://doi. org/10.1126/science.aaf1160 
Mohai, P., D. Pellow, and J. T. Roberts. 2009. Environmental justice. Annual Review of Environment and Resources 34:405-430. https://doi.org/10.1146/annurev-environ-082508-094348

Moore, M.-L., O. Tjornbo, E. Enfors, C. Knapp, J. Hodbod, J. Baggio, A. Norström, P. Olsson, and D. Biggs. 2014. Studying the complexity of change: toward an analytical framework for understanding deliberate social-ecological transformations. Ecology and Society 19(4):54. https://doi.org/10.5751/ES-06966-190454

Nemec, K. T., J. N. Chan, C. Hoffman, T. L. Spanbauer, J. A. Hamm, C. R. Allen, T. Hefley, D. Pan, and P. Shrestha. 2014. Assessing resilience in stressed watersheds. Ecology and Society 19(1):34. https://doi.org/10.5751/ES-06156-190134

Neuman, K. 2016. Canadian public opinion on aborigional peoples. Environics Institute for Survey Research, Toronto, Ontario, Canada.

Olsson, P., C. Folke, and T. Hahn. 2004. Social-ecological transformation for ecosystem management: the development of adaptive co-management of a wetland landscape in southern Sweden. Ecology and Society 9(4):2. https://doi.org/10.5751/ ES-00683-090402

Olsson, P., C. Folke, and T. P. Hughes. 2008. Navigating the transition to ecosystem-based management of the Great Barrier Reef, Australia. Proceedings of the National Academy of Sciences of the United States of America 105(28):9489-9494. https://doi. org/10.1073/pnas.0706905105

Olsson, P., L. Gunderson, S. Carpenter, P. Ryan, L. Lebel, C. Folke, and C. S. Holling. 2006. Shooting the rapids: navigating transitions to adaptive governance of social-ecological systems. Ecology and Society 11(1):18. https://doi.org/10.5751/ES-01595-110118

Österblom, H., J. B. Jouffray, C. Folke, B. Crona, M. Troell, A. Merrie, and J. Rockström. 2015. Transnational corporations as 'keystone actors' in marine ecosystems. Plos One 10(5). https:// doi.org/10.1371/journal.pone.0127533

Oteros-Rozas, E., B. Martin-López, T. M. Daw, E. L. Bohensky, J. R. A. Butler, R. Hill, J. Martin-Ortega, A. Quilan, F. Ravera, I. Ruiz-Mallén, et al. 2015. Participatory scenario planning in place-based social-ecological research: insights and experiences from 23 case studies. Ecology and Society 20(4):32. https://doi. org/10.5751/ES-07985-200432

Pinkerton, E., and L. John. 2008. Creating local management legitimacy. Marine Policy 32(4):680-691. https://doi.org/10.1016/ j.marpol.2007.12.005

Plagányi, E. E., I. van Putten, T. Hutton, R. A. Deng, D. Dennis, S. Pascoe, T. Skewes, and R. A. Campbell. 2013. Integrating indigenous livelihood and lifestyle objectives in managing a natural resource. Proceedings of the National Academy of Sciences of the United States of America 110(9):3639-3644. https://doi. org/10.1073/pnas.1217822110

Powell, M. 2012. Divided waters: Heiltsuk spatial management of herring fisheries and the politics of native sovereignty. Western Historical Quarterly 43(4):463-484. https://doi.org/10.2307/ westhistquar.43.4.0463

Price, K., A. Roburn, and A. MacKinnon. 2009. Ecosystem-based management in the Great Bear Rainforest. Forest Ecology and Management 258(4):495-503. https://doi.org/10.1016/j.foreco.2008.10.010
Quinlan, A. E., M. Berbes-Blázquez, J. L. Haider, and G. D. Peterson. 2015. Measuring and assessing resilience: broadening understanding through multiple disciplinary perspectives. Journal of Applied Ecology 53(3):677-687. https://doi.org/10.1111/1365-$\underline{2664.12550}$

Raudsepp-Hearne, C., G. D. Peterson, M. Tengö, E. M. Bennett, T. Holland, K. Benessaiah, G. K. MacDonald, and L. Pfeifer. 2010. Untangling the environmentalist's paradox: Why is human well-being increasing as ecosystem services degrade? Bioscience 60(8):576-589. https://doi.org/10.1525/bio.2010.60.8.4

Raworth, K. 2012. A safe and just space for humanity. Discussion Paper, Oxfam, Oxford, UK.

R Core Team. 2017. R: a language and environment for statistical computing. Foundation for Statistical Computing, Vienna, Austria. https://www.R-project.org/

Rockström, J., W. Steffen, K. Noone, A. Persson, F. S. Chapin, E. F. Lambin, T. M. Lenton, M. Scheffer, C. Folke, H. J. Schellnhuber, B. Nykvist, C. A. de Wit, T. Hughes, S. van der Leeuw, H. Rodhe, S. Sorlin, P. K. Snyder, R. Costanza, U. Svedin, M. Falkenmark, L. Karlberg, R. W. Corell, V. J. Fabry, J. Hansen, B. Walker, D. Liverman, K. Richardson, P. Crutzen, and J. A. Foley. 2009. A safe operating space for humanity. Nature 461 (7263):472-475. https://doi.org/10.1038/461472a

Rogers, L. A., A. K. Salomon, B. Connors, and M. Krkošek. 2018. Collapse, tipping points, and spatial demographic structure arising from the adopted migrant life history. American Naturalist 192(1):49-61. https://doi.org/10.1086/697488

Salomon, A. K., K. Lertzman, K. Brown, K. B. Wilson, D. Secord, and I. McKechnie. 2018. Democratizing conservation science and practice. Ecology and Society 23(1):44. https://doi. org/10.5751/ES-09980-230144

Salomon, A. K., N. Tanape, and H. Huntington. 2007. Serial depletion of marine invertebrates leads to the decline of a strongly interacting grazer. Ecological Applications 17(6):1752-1770. https://doi.org/10.1890/06-1369.1

Schindler, D. E., R. Hilborn, B. Chasco, C. P. Boatright, T. P. Quinn, L. A. Rogers, and M. S. Webster. 2010. Population diversity and the portfolio effect in an exploited species. Nature 465(7298):609-612. https://doi.org/10.1038/nature09060

Schlager, E., and E. Ostrom. 1999. Property rights regimes and coastal fisheries: an empirical analysis. In M. D. McGinnis, editor. Polycentric governance and development: readings from the workshop in political theory and policy analysis. University of Michigan Press, Ann Arbor, Michigan, USA.

Schultz, L., C. Folke, H. Österblom, and P. Olsson. 2015. Adaptive governance, ecosystem management, and natural capital. Proceedings of the National Academy of Sciences of the United States of America 112(24):7369-7374. https://doi.org/10.1073/ pnas. 1406493112

Shelton, A. O., J. F. Samhouri, A. C. Stier, and P. S. Levin. 2014. Assessing trade-offs to inform ecosystem-based fisheries management of forage fish. Scientific Reports 4:7110. https://doi. org/10.1038/srep07110 
Siple, M. C., and T. B. Francis. 2016. Population diversity in Pacific herring of the Puget Sound, USA. Oecologia 180 (1):111-125. https://doi.org/10.1007/s00442-015-3439-7

Tengö, M., E. S. Brondizio, T. Elmqvist, P. Malmer, and M. Spierenburg. 2014. Connecting diverse knowledge systems for enhanced ecosystem governance: the multiple evidence base approach. Ambio 43(5):579-591. https://doi.org/10.1007/ $\underline{\text { s13280-014-0501-3 }}$

Tengö, M., R. Hill, P. Malmer, C. M. Raymond, M. Spierenburg, F. Danielsen, T. Elmqvist, and C. Folke. 2017. Weaving knowledge systems in IPBES, CBD and beyond-lessons learned for sustainability. Current Opinion in Environmental Sustainability 26-27:17-25. https://doi.org/10.1016/j.cosust.2016.12.005

Trosper, R. 2009. Resilience, reciprocity and ecological economics: Northwest Coast sustainability. Routledge, New York, New York, USA. https://doi.org/10.4324/9780203881996

Turner, N. J., F. Berkes, J. Stephenson, and J. Dick. 2013. Blundering intruders: extraneous impacts on two Indigenous food systems. Human Ecology 41(4):563-574. https://doi. org/10.1007/s10745-013-9591-y

von der Porten, S., D. Lepofsky, D. McGregor, and J. Silver. 2016. Recommendations for marine herring policy change in Canada: aligning with Indigenous legal and inherent rights. Marine Policy 74:68-76. https://doi.org/10.1016/j.marpol.2016.09.007

Walker, B., C. S. Holling, S. R. Carpenter, and A. Kinzig. 2004. Resilience, adaptability and transformability in social-ecological systems. Ecology and Society 9(2):5. https://doi.org/10.5751/ ES-00650-090205

Waylen, K., K. Blackstock, and K. Holstead. 2015. How does legacy create sticking points for environmental management? Insights from challenges to implementation of the ecosystem approach. Ecology and Society 20(2):21. https://doi.org/10.5751/ ES-07594-200221

Westley, F., P. Olsson, C. Folke, T. Homer-Dixon, H. Vredenburg, D. Loorbach, J. Thompson, M. Nilsson, E. Lambin, J. Sendzimir, et al. 2011. Tipping toward sustainability: emerging pathways of transformation. AMBIO 40(7):762-780. https://doi.org/10.1007/ s13280-011-0186-9

Westley, F. R., O. Tjornbo, L. Schultz, P. Olsson, C. Folke, B. Crona, and Ö. Bodin. 2013. A theory of transformative agency in linked social-ecological systems. Ecology and Society 18(3):27. https://doi.org/10.5751/ES-05072-180327 


\section{APPENDIX 1}

2 Table A1.1 Quantitative resilience questionnaire of Pacific herring social-ecological system

3 resilience. Questions were answered based on a Likert scale from 1 (low) to 5 (high) for each 4 governance era.

\begin{tabular}{|c|c|c|}
\hline $\begin{array}{l}\text { Resilience } \\
\text { Principle }\end{array}$ & Metric & Question \\
\hline \multirow{6}{*}{$\begin{array}{l}\text { Maintain } \\
\text { Diversity \& } \\
\text { Redundancy }\end{array}$} & Marine Species \& & How would you rank the variety of marine species \\
\hline & $\begin{array}{l}\text { Species Response } \\
\text { Diversity }\end{array}$ & $\begin{array}{l}\text { How would you rank the variety of ways in which } \\
\text { these marine species respond to abrupt ecological, } \\
\text { social, or economic disturbances? }\end{array}$ \\
\hline & $\begin{array}{l}\text { Diversity of } \\
\text { Perspectives }\end{array}$ & $\begin{array}{l}\text { How would you rank the variety of perspectives } \\
\text { (ex: ideas, views, opinions) that inform decision- } \\
\text { making in Central Coast herring fisheries? }\end{array}$ \\
\hline & $\begin{array}{l}\text { Diversity of } \\
\text { Livelihoods }\end{array}$ & $\begin{array}{l}\text { How would you rank the variety of occupations in } \\
\text { which Central Coast First Nations participate? }\end{array}$ \\
\hline & $\begin{array}{l}\text { Diversity in Herring } \\
\text { Size Structure }\end{array}$ & $\begin{array}{l}\text { How would you rank the relative abundance of } \\
\text { large-sized individual herring in Central Coast } \\
\text { populations? }\end{array}$ \\
\hline & $\begin{array}{l}\text { Diversity in Herring } \\
\text { Spawning Season } \\
\text { Dates }\end{array}$ & $\begin{array}{l}\text { How would you rank the length of the spawning } \\
\text { season along the Central Coast? }\end{array}$ \\
\hline $\begin{array}{l}\text { Manage } \\
\text { Connectivity }\end{array}$ & $\begin{array}{l}\text { Degree of } \\
\text { Information Sharing }\end{array}$ & $\begin{array}{l}\text { How connected are ALL the groups involved in the } \\
\text { Central Coast herring fisheries in terms of } \\
\text { information sharing? }\end{array}$ \\
\hline \multirow[t]{2}{*}{$\begin{array}{l}\text { Manage Slow } \\
\text { Variables \& } \\
\text { Feedbacks }\end{array}$} & $\begin{array}{l}\text { Understanding of } \\
\text { Gradual Changes }\end{array}$ & $\begin{array}{l}\text { How would you rank decision-makers' } \\
\text { understanding of gradual, long-term changes along } \\
\text { the Central Coast (Ex: Slow changes in ocean } \\
\text { productivity, people’s values etc...)? }\end{array}$ \\
\hline & $\begin{array}{l}\text { Decisions Updated } \\
\text { With New } \\
\text { Information }\end{array}$ & $\begin{array}{l}\text { How would you rank the level to which information } \\
\text { about the entire system is used and then evaluated } \\
\text { in decision-making? }\end{array}$ \\
\hline
\end{tabular}




Ability of Managers
to Respond to Key
Changes

Foster Complex

Adaptive

Thinking

\section{Encourage \\ Learning}

Broaden

Participation

Promote

Polycentric

Governance
Willingness to

Embrace Change

Preparedness to

Cope with

Unexpected Events

Innovation \&

Willingness to

Experiment

Sharing of

Scientific Resources

Level of

Participation

Level of Trust

Level of

Cooperation

Use of Indigenous

Knowledge \&

Stewardship

Protocols

Distribution of

Power in Decision

Making

Accountability
How would you rank the ability of managers to respond to important changes (ecological, economic, \& social)?

How would you rank the willingness to embrace change in the Central Coast herring fisheries?

How prepared is the herring system to cope with unexpected events?

How would you rank innovation (Ex. experimentation) in the management of Central Coast herring fisheries?

How would you rank communication and the sharing of scientific resources (data, research boats, and modeling tools) across government bodies in the herring fisheries?

How would you rank the level of participation of all users in decision-making?

How would you rank the level of trust among ALL governing institutions of the Central Coast herring fisheries?

How would you rank the level of cooperation among groups involved in decision-making?

How would you rank the use and integration of First Nations knowledge and stewardship protocols in the management of herring fisheries?

How would you rank the distribution of power in decision-making around the herring fisheries?

How would you rank the accountability (following through on responsibilities) among governments in the herring fisheries? 
Indigenous How would you rank Central Coast First Nations' Authority to Access authority to access herring?

Herring

Willingness for

How would you rank the willingness for conflict Conflict Resolution resolution and negotiation among decision-makers in the herring fisheries? 
APPENDIX 2

\section{Governance regimes}

Archaeological and ethnographic evidence suggests that an Indigenous Governance era began at least 2000 years ago when formal and informal institutions were used to manage natural resources (Trosper 2002, Trosper 2009), including Pacific herring fisheries (Powell 2012). Exclusive rights to ocean spaces were held by Chiefs and proprietorship was contingent on management that sustained productive resources within the titleholders' territory. Systems of reciprocity defined economic exchange among individuals and groups, incentivizing sustainable use and providing insurance within a titleholder's territory. Chiefs were made accountable to uphold these rules of reciprocity and proprietorship via the potlatch, a system of governance that was widespread along the west coast of Canada (Trosper 2002, Trosper 2009). For the Heiltsuk Nation, these principles are embodied within Gvi'las, the body of traditional knowledge and system of rules, beliefs and practices governing resource use and stewardship within their territory (Powell 2012, Housty et al. 2014, Gauvreau et al. 2017). Throughout, Pacific herring have played a crucial role in Indigenous livelihoods as a trade commodity, important source of food, oil and bait, and as a key component of ceremonial and social traditions (Brown and Brown 2009, McKechnie et al. 2014). Although colonization began in the early 1800s, leading to the erosion of Indigenous economies and governance structure, and the introduction of pandemic diseases (Boyd 1999), Indigenous governance structures were significantly crippled with the banning of the potlatch in 1885 (Cole and Chaikin 1990), albeit to vary degrees among coastal First Nations.

The Colonial Control era was characterized by state-control over fisheries and other aspects of coastal First Nations' society. During this time, Indigenous access to and trade of herring was controlled by externally enforced rules. First Nations were granted the right to fish for food 'but not for sale, barter or traffic' and the reserve system displaced Indigenous fishers from many traditional harvesting areas (Harris 2000, Harris 2008). By excluding Indigenous people from commercial fisheries and limiting their cultural, political and economic practices related to herring (Turner et al. 2008), these rules created a space into which the state could insert its own management authority. Throughout this era and since then, Canada's federal department of fisheries has asserted its authority over all fisheries in Canada under the Fisheries Act (Canada 1985), even though most coastal Indigenous communities in BC have not signed treaties relinquishing ownership or control of their lands and sea. In the late 1800s, new fishing technologies enabled industrial herring fisheries, including a bait and dry-salted fishery, and a large reduction fishery (Jones et al. 2017). Overfishing led to the first coast-wide herring stock collapse in 1967 and the closure of all herring fisheries in BC from 1968 to 1972 (Jones et al. 2017). Shortly after, herring fisheries were reopened targeting new international markets for herring eggs.

The third governance regime, the Environmental Justice era, was triggered by local revolt. It began when the exclusion of First Nations fishers from the commercial spawn-on-kelp fishery motivated two Heiltsuk brothers to be purposefully charged with illegally selling herring eggs without a permit in order to challenge the law (Powell 2012). This event lead to a 
precedent-setting Supreme Court of Canada case in 1996 that established the Heiltsuk Nation's aboriginal right to commercially harvest herring spawn-on kelp (R.v.Gladstone 1996). More than two decades later, negotiations continue over the implementation of these rights. The discrepancy between the court's recognition and affirmation of aboriginal fishing rights to herring and the translation of these rights into herring policy have resulted in coast wide protests by Indigenous groups from 1998 to present (Jones et al. 2017). This current governance era is characterized by continued efforts among the Heiltsuk and neighbouring First Nations to change how the herring fishery system is governed and managed (von der Porten et al. 2016, Jones et al. 2017). Despite declines in herring biomass and conservation concerns by several First Nations communities, Canada's federal fisheries department opened the commercial herring fishery in 2014 and 2015 amid protests. Local objection on the central coast of BC culminated in the occupation of a federal government office, triggering the 2015 herring fishery crisis.

\section{LITERATURE CITED}

Boyd, R. T. 1999. The coming of the spirit of pestilence: Introduced infectious diseases and population decline among Northwest Coast indians, 1774-1874. University of Washington and University of British Columbia Press, Vancouver, Toronto. fundamental truths: Biodiversity, stewardship and sustainability. Biodiversity BC, Victoria.

Cole, D. and I. Chaikin. 1990. An iron hand upon the people: The law against the potlatch on the Northwest Coast. Douglas \& McIntyre, Vancouver, Toronto. 
77 Jones, R., C. Rigg and E. Pinkerton. 2017. Strategies for assertion of conservation and local

78 management rights: A Haida Gwaii herring story. Marine Policy 80:154-167.

79 McKechnie, I., D. Lepofsky, M. L. Moss, V. L. Butler, T. J. Orchard, G. Coupland, F. Foster, M. 80 Caldwell and K. Lertzman. 2014. Archaeological data provide alternative hypotheses on Pacific 81 herring (Clupea pallasii) distribution, abundance, and variability. Proceedings of the National

82 Academy of Sciences of the United States of America 111(9):E807-E816.

83 Powell, M. 2012. Divided waters: Heiltsuk spatial management of herring fisheries and the 84 politics of native sovereignty. Western Historical Quarterly 43:463-484.

85 R.v.Gladstone. 1996. 723. S.C.R.

86 Trosper, R. 2009. Resilience, Reciprocity and Ecological Economics. Routledge, New York, NY.

87 Trosper, R. L. 2002. Northwest coast indigenous institutions that supported resilience and

88 sustainability. Ecological Economics 41(2):329-344.

89 Turner, N. J., R. Gregory, C. Brooks, L. Failing and T. Satterfield. 2008. From Invisibility to

90 Transparency: Identifying the Implications. Ecology and Society 13(2):7.

91 von der Porten, S., D. Lepofsky, D. McGregor and J. Silver. 2016. Recommendations for marine 92 herring policy change in Canada: Aligning with Indigenous legal and inherent rights. Marine 93 Policy 74:68-76. 


\section{APPENDIX 3}

2 Table A3.1 Results of analysis of deviance (Type II) for two nested ordinal logistic mixed-

3 effects models of A) overall social-ecological system (SES) resilience and B) specific resilience

4 principle. We detected a significant effect of governance regime (Indigenous, Colonial Control

5 and Environmental Justice) on the resilience of the Pacific herring social-ecological system. The

6 magnitude of this effect varied among the seven resilience principles and among the metrics we

7 used to assess each resilience principle.

9

\begin{tabular}{lllcc}
\hline \hline Response Variable & Factors & $\begin{array}{l}\text { Likelihood } \\
\text { Ratio Chi } \\
\text { square }\end{array}$ & Df & $\begin{array}{l}\operatorname{Pr}(>\mathrm{Chi} \\
\text { square })\end{array}$ \\
\hline $\begin{array}{l}\text { A) Overall SES } \\
\text { Resilience }\end{array}$ & Governance Regime & 432.2 & 2 & $<2.2 \mathrm{e}^{-16}$ \\
& Governance Regime(Resilience Principle) & 122.3 & 18 & $<2.2 \mathrm{e}^{-16}$ \\
$\begin{array}{l}\text { B) Resilience } \\
\text { Principle }\end{array}$ & Governance Regime & 432.2 & 2 & $<2.2 \mathrm{e}^{-16}$ \\
& Governance Regime(Resilience Metric) & 259.2 & 63 & $<2.2 \mathrm{e}^{-16}$ \\
\hline
\end{tabular}




\section{APPENDIX 4}

2 Table A4.1 Pair-wise contrasts evaluating the effect of governance regime (Indigenous, Colonial

3 Control and Environmental Justice) on overall social-ecological system resilience assessed for 4 each of Biggs et al.’s (2012) seven resilience principles. P-values adjusted via Tukey method.

5 Bold = significant, non-bold = not significant. The magnitude and significance of the effect of 6 governance regime on each resilience principle varied between the three governance regimes.

\begin{tabular}{|c|c|c|c|}
\hline Resilience Principle & $\begin{array}{l}\text { Indigenous vs. } \\
\text { Colonial Control }\end{array}$ & $\begin{array}{l}\text { Colonial Control vs. } \\
\text { Environmental } \\
\text { Justice }\end{array}$ & $\begin{array}{l}\text { Environmental Justice vs. } \\
\text { Indigenous }\end{array}$ \\
\hline $\begin{array}{l}\text { Manage Diversity \& } \\
\text { Redundancy }\end{array}$ & $<0.0001$ & $<0.0001$ & $<0.0001$ \\
\hline Manage Connectivity & $<0.0001$ & 0.8021 & $<0.0001$ \\
\hline $\begin{array}{l}\text { Manage Slow } \\
\text { variables }\end{array}$ & $<0.0001$ & 0.8999 & $<0.0001$ \\
\hline $\begin{array}{l}\text { Complex Adaptive } \\
\text { Systems Thinking }\end{array}$ & 0.0235 & 0.3997 & 0.0004 \\
\hline Encourage Learning & $<0.0001$ & 0.9463 & 0.0001 \\
\hline Broaden Participation & $<0.0001$ & 0.2222 & $<0.0001$ \\
\hline $\begin{array}{l}\text { Promote Polycentric } \\
\text { Governance }\end{array}$ & $<0.0001$ & 0.8273 & $<0.0001$ \\
\hline
\end{tabular}




\section{APPENDIX 5}

2 Table A5.1 Pair-wise contrasts evaluating the effect of governance regime (Indigenous, Colonial

3 Control and Environmental Justice) on each resilience metric ( $\mathrm{n}=22)$. P-values adjusted via

4 Tukey method. Bold = significant, non-bold = not significant. The effect of Governance Regime

5 differed among the metrics we used to assess each resilience principle.

6

\begin{tabular}{|c|c|c|c|c|}
\hline "Resilience Principle & Metric & $\begin{array}{l}\text { Indigenous vs. } \\
\text { Colonial Control }\end{array}$ & $\begin{array}{l}\text { Colonial Control } \\
\text { vs. Environmental } \\
\text { Justice }\end{array}$ & $\begin{array}{l}\text { Environmental } \\
\text { Justice vs. } \\
\text { Indigenous }\end{array}$ \\
\hline \multirow[t]{6}{*}{$\begin{array}{l}\text { Manage Diversity \& } \\
\text { Redundancy }\end{array}$} & $\begin{array}{l}\text { Marine Species \& } \\
\text { Habitat Diversity }\end{array}$ & 0.0032 & 0.0006 & $<0.0001$ \\
\hline & $\begin{array}{l}\text { Species Response } \\
\text { Diversity }\end{array}$ & 0.4136 & 0.1528 & 0.0059 \\
\hline & $\begin{array}{l}\text { Diversity of } \\
\text { Perspectives }\end{array}$ & 0.0024 & 0.7390 & 0.0002 \\
\hline & $\begin{array}{l}\text { Diversity of } \\
\text { Livelihoods }\end{array}$ & 0.0001 & 0.5567 & $<0.0001$ \\
\hline & $\begin{array}{l}\text { Diversity in Herring } \\
\text { Size Structure }\end{array}$ & $<0.0001$ & $<0.0001$ & $<0.0001$ \\
\hline & $\begin{array}{l}\text { Diversity in Herring } \\
\text { Spawning Season } \\
\text { Dates }\end{array}$ & 0.0006 & $<0.0001$ & $<0.0001$ \\
\hline Manage Connectivity & $\begin{array}{l}\text { Degree of Information } \\
\text { Sharing }\end{array}$ & $<0.0001$ & 0.7737 & $<0.0001$ \\
\hline \multirow[t]{3}{*}{$\begin{array}{l}\text { Manage Slow } \\
\text { variables }\end{array}$} & $\begin{array}{l}\text { Understanding of } \\
\text { Gradual Changes }\end{array}$ & $<0.0001$ & 0.9111 & 0.0001 \\
\hline & $\begin{array}{l}\text { Decisions Updated } \\
\text { With New } \\
\text { Information }\end{array}$ & 0.0001 & 0.6176 & $<0.0001$ \\
\hline & $\begin{array}{l}\text { Ability of Managers to } \\
\text { Respond to Key } \\
\text { Changes }\end{array}$ & 0.0036 & 0.9696 & 0.0026 \\
\hline
\end{tabular}




\begin{tabular}{|c|c|c|c|c|}
\hline \multirow{3}{*}{$\begin{array}{l}\text { Complex Adaptive } \\
\text { Systems Thinking }\end{array}$} & Willingness to & 0.2168 & 0.9560 & 0.1355 \\
\hline & Embrace Change & & & \\
\hline & $\begin{array}{l}\text { Preparedness to Cope } \\
\text { with Unexpected } \\
\text { Events }\end{array}$ & 0.0679 & 0.2533 & 0.0006 \\
\hline \multirow[t]{2}{*}{ Encourage Learning } & $\begin{array}{l}\text { Innovation \& } \\
\text { Willingness to } \\
\text { Experiment }\end{array}$ & 0.0002 & 0.7774 & $<0.0001$ \\
\hline & $\begin{array}{l}\text { Sharing of Scientific } \\
\text { Resources }\end{array}$ & 0.0167 & 0.5219 & 0.1813 \\
\hline \multirow{3}{*}{$\begin{array}{l}\text { Broaden } \\
\text { Participation }\end{array}$} & Level of Participation & $<0.0001$ & 0.4453 & $<0.0001$ \\
\hline & Level of Trust & $<0.0001$ & 0.2782 & $<0.0001$ \\
\hline & Level of Cooperation & $<0.0001$ & 0.9756 & $<0.0001$ \\
\hline \multirow[t]{5}{*}{$\begin{array}{l}\text { Promote Polycentric } \\
\text { Governance }\end{array}$} & $\begin{array}{l}\text { Use of Indigenous } \\
\text { Knowledge \& } \\
\text { Stewardship Protocols }\end{array}$ & $<0.0001$ & 0.4924 & $<0.0001$ \\
\hline & $\begin{array}{l}\text { Distribution of Power } \\
\text { in Decision Making }\end{array}$ & 0.1216 & 0.9864 & 0.0797 \\
\hline & Accountability & $<0.0001$ & 0.4318 & $<0.0001$ \\
\hline & $\begin{array}{l}\text { Indigenous Authority } \\
\text { to Access Herring }\end{array}$ & $<0.0001$ & 0.7448 & 0.0001 \\
\hline & $\begin{array}{l}\text { Willingness for } \\
\text { Conflict Resolution }\end{array}$ & $<0.0001$ & 0.5467 & 0.0003 \\
\hline
\end{tabular}

